\title{
Peran Media Cetak Pada Pilkada Gubernur dan Wakil Gubernur NTB Tahun 2018 \\ (Analisis Isi Berita Pilkada Gubernur dan Wakil Gubenur NTB \\ Edisi 1-31 Maret 2018 Pada Harian Suara NTB)
}

\author{
Subhannur ${ }^{1}$, YulandaTrisula SY ${ }^{2}$, I Made Putra Suryantara ${ }^{3}$ \\ Program Studi Ilmu Komunikasi Fakultas Ilmu Sosial dan Ilmu Politik \\ Universitas 45 Mataram \\ Subhannur913@gmail.com
}

\begin{abstract}
The objectives of this study are: 1). to find out the neutrality of the local print media in the Suara Barat NTB in covering news regarding NTB governor-deputy governor election edition March 1-31 2018, 2). to find out how far the application of the Indonesian Journalists Journalist Code of Ethics by the Media Print of the Daily Voice of NTB on the election of the governor and deputy governor of NTB edition March 1-31 in 2018.

The results shows that the frequency of the candidates reported was $51.9 \%$ of the Ali-Sakti pair, 24.03\% of the pair of Akhyar-Mori, 13.4\% of ZulRohmi pair and lastly the remaining $10.57 \%$ of the Suhaili-Amin pair.This calculation shows that the news of the NTB governor and deputy governor candidate pair in 2018 regional election leaned more towards the Ali-Sakti pair. Thus, the neutrality of the NTB voting media towards the pair of candidates and the application of the Indonesian Journalists Journalist Code of Ethics, especially in terms of presenting news in a balanced manner, still need improvement.
\end{abstract}

Keyword: The Role of Media Print on Governor Election 


\begin{abstract}
ABSTRAK
Tujuan dari penelitian ini adalah : 1). Untuk mengetahui netralitas media cetak lokal Harian Suara NTB dalam menyampaikan berita pilkada gubernur dan wakil gubernur NTB edisi 1-31 Maret 2018. 2). Untuk mengetahui sejauh mana penerapan Kode Etik Jurnalis Wartawan Indonesia oleh Media Cetak Harian Suara NTB pada pemberitaan pilkada gubernur dan wakil gubernur NTB edisi 1-31 Maret tahun 2018.

Hasil Penelitian menunjukkan bahwa, frekuensi kandidat yang diberitakan adalah sebanyak 51,9\% Pasangan Calon Ali-Sakti, 24,03\% memberitakan Pasangan Calon Akhyar-Mori, 13,4\% memberitakan Pasangan Calon Zul-Rohmi dan 10,57\% memberitakan Pasangan Calon Suhaili-Amin. Perhitungan ini menunjukkan bahwa pmberitaan pasangan calon gubernur dan wakil gubernur NTB pada pilkada tahun 2018 lebih condong kepada pasangan Ali-Sakti, dengan demikian netralitas media cetak Suara NTB terhadap pasangan calon dan penerapan Kode Etik Jurnalis Wartawan Indonesia terutama dalam hal menyajikan berita secara berimbang masih perlu ditingkatkan.
\end{abstract}

\title{
Kata kunci : Peran Media Cetak Pada Pilkada Gubernur
}

\section{PENDAHULUAN}

Penyampain informasi melalui media masa saat ini dapat dilakukan secara langsung maupun secara tidak langsung, dimana media yang digunakan antara lain dapat berupa media cetak seperti surat kabar, majalah, media elektronik seperti radio, televisi bahkan internet, sehingga masyarakat memiliki kebebasan untuk memilih informasi yang diterima sesuai dengan kebutuhannya

Dikemukakakan Bittner, (dalam Imran, 2012). mass communication is message given through a mass medium to a number of people, atau komunikasi massa diartikan sebagai pesan yang dikomunikasikan melalui media massa kepada sekolompok orang. Dari sekian banyak definisi bisa dikatakan media massa bentuknya antara lain media elektronik (televisi,radio) dan media cetak (surat kabar, majalah, tabloid), buku dan film (Nurudin, 2017:3-4)

Saat ini media cetak tetap menjadi salah satu sumber informasi yang terpercaya. Salah satu media cetak Iokal di Nusa Tenggara Baratyang terbit setiap hari adalah Koran Suara NTB yang menyajikan informasi penting terkait Pilkada gubernur dan wakil gubernur Provinsi Nusa Tengara Barat tahun 2018.

Mempertimbangkan hal-hal di atas penulis bermaksud untuk melakukan analisis isi berita pilkada untuk mengetahui netralitas media dalam 
penyajian berita dan penerapan Kode Etik Jurnalistik Wartawan Indonesia dengan judul penelitian "Peran Media Cetak Pada Pilkada Gubernur dan Wakil Gubernur NTB Tahun 2018 (Analisisi isi Berita Pilkada gubernur dan wakil gubernur NTB Edisi 1-31 Maret 2018 di Harian Suara NTB)”.

\section{METODOLOGI PENELITIAN}

Metode penelitian yang digunakan adalah Analisis isi kuantitatif yakni analisisi isi yang dipakai untuk mengukur aspek-aspek tertentu dari berita yang dilakukan secara kuantitatif. Prosedurnya ialah dengan jalan mengukur dan menghitung aspek dari berita itu dan memfokuskanya pada bahan yang tersurat saja secara kuantitatif dengan cara meng-coding atau memberi tanda. (Eriyanto, 2011: 412)

Secara umum, analisis kuantitatif dapat didefinisikan sebagai suatu teknik penelitian ilmiah yang ditujukan untuk mengetahui gambaran karakteristik isi dan menarik inferensi dari isi dengan tujuan untuk mengidentifikasi secara sitematis isi komunikasi yang tampak dan dilakukan secara objektif, valid,relibel dan dapat direplikasi. (Eriyanto, 2011:15)

Lembar coding (coding shet) adalah alat yang dipakai untuk mengukur aspek tertentu dari isi media yang memuat aspek-aspek apa saja yang ingin kita liat dalam analisisi isi seperti imformasi umum berita, Narasumber berita dan kecenderungan berita. (Eriyanto, 2011:221)

Populasi pada penelitian ini adalah semua berita pilkada gubernur dan wakil gubernur Provinsi Nusa Tenggara Barat (NTB) pada Headline Surat Kabar Harian Suara NTB edisi bulan Januari hingga Mei 2018. Sampel dalam penelitian ini adalah untuk unit pengamatan yaitu Headline berita pilkada gubernur dan wakil gubernur NTB tahun 2018, edisi 1-31 Maret 2018. Alasannya adalah pada bulan ini sedang gencar-gencarnya kampanye pasangan calon.

Teknik pengumpulan data merupakan langkah yang paling strategis dalam penelitian, karena tujuan utama dari penelitian adalah mendapatkan data (Sugiyono, 2016 :214-225). Dalam penelitia ini, peneliti menggunakan teknik pengumpulan data dengan metode observasi, dokumentasi dan studi pustaka.

a. Observasi, menurut Sutrisno Hadi (1986) mengemukakan bahwa, observasi merupakan suatu proses yang kompleks, suatu proses yang tersusun dari pelbagai proses biologis dan psikologis. (Sugiyono, 2016 :145)

b. Dokumentasi adalah mengambil gambar-gambar atau bentuk dan isi berita yang diperlukan dengan cara mengkliping berita pilkada gubernur dan wakil gubernur NTB edisi1-31 Maret 2018 pada Surat Kabar Harian 
Suara NTB, karena objek dari penelitian ini adalah berita di media masa (media cetak)

c. Wawancara, wawancara digunakan sebagai teknik pengumpulan data apabila ingin melakukan studi pendahuluan untuk menemukan permasalahan yang harus diteliti, dan juga apabila peneliti ingin mengetahui hal-hal dari responden yang lebih mendalam. (Sugiyono, 2016 :137)

Data yang akan digunakan dalam analisis penelitian ini adalah data primer dan data sekunder. Data primer didapat dari observasi, wawancara dan dokumentasi Berita Pilkada Gubernur dan Wakil Gubenur NTB Edisi 1-31 Maret 2018 di Harian Suara NTB , sedangkan data skunder didapat dari sumber-sumber lain yang menjadi referensi skunder bagi penelitian ini antara lain buku referenc, surat kabar atau jurnal yang dinilai relevan dengan obyek kajian.

Analisis data adalah proses penyederhanaan data dalam bentuk yang lebih mudah dibaca. Data yang sudah terkumpul dalanm bentuk lembar coding (coding shet) direkap untuk memudahkan pembacaan data dan analisisinya. Rekapitulasi data tersebut diinput kedalam softweare SPSS (Statistical Package for Social Science) ataupun di input dalam mixrosoft word dan Exel. Pertama peneliti akan melakukan uji reliabilitas dengan rumus yang dipopulerkan oleh R. Holsti (1969).

Reliabilitas ditunjukkan dalam presentase persetujuan berapa besar persentase persamaan antar-coder ketika menilai suatu isi. (Holsti dalam Eriyanto, 2011: 290). Rumusnya adalah

\section{Reliabilitas antar coder $=\frac{2 . \mathrm{M}}{N 1+N 2}$}

Dimana $\mathrm{M}$ adalah jumlah coding yang sama, (disetujui oleh masingmasing coder), $N 1$ adalah jumlah coding yang dibuat oleh coder $1, N 2$ adalah jumlah coding yang dibuat coder 2.

Reliabilitas bergerak antara 0-1. Dalam formula Holsti, angka reliabilitas minimum yang di toleransi adalah 0,7 atau $70 \%$, jika hasil perhitungan menunjukkan angaka reliabilitas diatas $0,7 \%$ berarti alat ukur ini benar-nenar reliabel. Tetapi, jika dibawah 0,7, berarti coding sheet (alat ukur) belum reliabel. (Eriyanto, 2011:290)

Tahap awal analisis data adalah mendeskripsikan temuan menggunakan statistik deskriptif. Disebut statistik deskriptif karena statistik ini 
bertujuan mendeskripsikan dan menjabarkan temuan dan data yang didapat dari analisis isi. (Eriyanto, 2011:306). Kemudian data yang ada dibuat dalam bentuk tabel frekuensi untuk memaparkan hasil datanya.Masing-masing unit analisis mempunyai satu tabel frekuensi

\section{HASIL PENELITIAN}

Tabel.1.

Frekuensi Unit Analisis Penempatan Berita Pasangan Calon berdasarkan hasil Coding Shet

\begin{tabular}{|l|c|c|c|c|c|c|}
\hline \multirow{2}{*}{$\begin{array}{c}\text { Pasngan } \\
\text { Calon }\end{array}$} & \multicolumn{5}{|c|}{ Frekuensi } & \multirow{2}{*}{ (Headline) } \\
\cline { 2 - 6 } & $\begin{array}{c}\text { Halaman } \\
\text { Depan } \\
\text { (bukan } \\
\text { Headline) }\end{array}$ & $\begin{array}{c}\text { Halaman } \\
\text { dalam }\end{array}$ & $\begin{array}{c}\text { Halaman } \\
\text { Khususus }\end{array}$ & $\begin{array}{c}\text { Halaman } \\
\text { Belakang }\end{array}$ & Total \\
\hline Suhaili-Amin & 0 & 1 & 4 & 6 & 0 & 11 \\
\hline Akhyar-Mori & 0 & 12 & 4 & 4 & 5 & 25 \\
\hline Zul-Rohmi & 0 & 4 & 5 & 4 & 0 & 13 \\
\hline Ali-Sakti & 51 & 1 & 0 & 2 & 0 & 58 \\
\hline Total & 51 & 18 & 13 & 16 & 5 & 103 \\
\hline
\end{tabular}

Sumber : Data olahan penulis, 2018

Tabel diatas menunjukkan, Frekuensi Pasangan Calon Ali-Sakti sebanyak 51 atau $100 \%$ berada di halaman depan (Headline), 2 atau 12,5\% di halaman khusus, 1 atau 5,5\% di halaman depan bukan Headline sedangkan Akhyar-Mori sebanyak 12 atau 66,6\% berada di halaman depan bukan Headline, 5 atau $100 \%$ di halaman belakang, 4 atau 30,7\% di halaman dalem, 4 atau $25 \%$ di halaman khusus.

Pasangan Calon Suhaili-Amin sebanyak 6 atau 37,5\% berada di halaman khusus, 4 atau 30,7\% berada di halaman dalem dan 1 atau 5,5\% di halaman depan bukan Headline dan pasangan Calon Zul-Rohmi sebanyak 5 atau $38,4 \%$ berada dihalaman dalem, 4 atau 22,2\% di halaman depan bukan hidline, 4 atau $25 \%$ di halaman khusus. 
Tabel.2.

Frekuensi Unit Asal Berita Pasangan Calon

berdasarkan hasil Coding Shet

\begin{tabular}{|l|c|c|c|c|c|}
\hline \multirow{2}{*}{$\begin{array}{c}\text { Pasangan } \\
\text { Calon }\end{array}$} & \multicolumn{4}{|c|}{ Frekuensi } & \multirow{2}{*}{ Total } \\
\cline { 2 - 5 } & $\begin{array}{c}\text { Keterangan } \\
\text { Pers }\end{array}$ & $\begin{array}{c}\text { Liputan } \\
\text { Langsung }\end{array}$ & $\begin{array}{c}\text { Mengutip } \\
\text { Media Lain }\end{array}$ & Lainnya & \\
\hline Suhaili-Amin & 7 & 3 & 0 & 0 & 10 \\
\hline Akhyar-Mori & 6 & 16 & 0 & 0 & 22 \\
\hline Zul-Rohmi & 5 & 8 & 0 & 0 & 13 \\
\hline Ali-Sakti & 35 & 18 & 0 & 0 & 53 \\
\hline Total & 53 & 45 & 0 & 0 & 98 \\
\hline
\end{tabular}

Sumber : Data olahan penulis, 2018

Berdasarkan tabel diatas, frekuensi asal berita Pasangan Calon AliSakti sebanyak 35 atau 66,3\% dari keterangan pers dan 18 atau $40 \%$ dari liputan langsung sedangkan frekuensi keterangan pers asal berita Pasangan Calon Suhaili-Amin sebanyak 7 atau 13,2\% dari keterangan pers dan 3 atau $6,6 \%$ liputan langsung. Untuk frekuensi asal berita Pasangan Calon AkhyarMori sebanyak 6 atau 11,3\% keterangan pers, liputan langsung sebanyak 16 atau 35,5\%, kemudian frekuensi asal berita Pasangan Calon Zul-Rohmi sebanyak 5 atau $0,4 \%$ keterangan pers, liputan langsung sebanyak 8 atau $17,7 \%$

Tabel.3.

Frekuensi Unit Analisis Topik Berita Pasangan Calon berdasarkan hasil Coding Shet

\begin{tabular}{|c|c|c|c|c|c|c|c|}
\hline \multirow[b]{2}{*}{$\begin{array}{l}\text { Pasangan } \\
\text { Calon }\end{array}$} & \multicolumn{6}{|c|}{ Frekuensi } & \multirow[b]{2}{*}{ Total } \\
\hline & $\begin{array}{c}\text { Profil } \\
\text { Kandiadat }\end{array}$ & $\begin{array}{c}\text { Isu } \\
\text { Ekonomi }\end{array}$ & $\begin{array}{c}\text { Isu } \\
\text { Sosial }\end{array}$ & $\begin{array}{c}\text { Isu } \\
\text { Politik }\end{array}$ & $\begin{array}{c}\text { Isu } \\
\text { Persaingan } \\
\text { Pemlihan }\end{array}$ & $\begin{array}{c}\text { Isu } \\
\text { Ideologi }\end{array}$ & \\
\hline Suhaili-Amin & 0 & 2 & 0 & 7 & 1 & 0 & 10 \\
\hline Akhyar-Mori & 0 & 7 & 2 & 14 & 0 & 0 & 23 \\
\hline Zul-Rohmi & 1 & 3 & 1 & 7 & 0 & 0 & 12 \\
\hline Ali-Sakti & 27 & 9 & 6 & 5 & 3 & 4 & 54 \\
\hline Total & 28 & 21 & 9 & 33 & 4 & 4 & 99 \\
\hline
\end{tabular}

Sumber : Data olahan penulis, 2018

Tabel datas menunujukkan frekuensi topik berita Pasangan Calon AliSakti sebanyak 27 atau 96,4\% tentang profil kandidat, 9 atau $42 \%$ isu ekonomi, 
6 atau 66\% dengan isu sosial, 5 atau 15,5\% dengan isu politik, 3 atau 75\% dengan isu persaingan pemilihan dan 4 atau $100 \%$ dengan isu ideologi. Frekuensi Topik berita Pasangan Calon Ahyar-Mori sebanyak 14 atau 42,4\% tentang isu politik, 7 atau 33,3\% isu ekonomi dan sebanyak 2 atau $22,2 \%$ isu sosial. Frekuensi topik berita Pasangan Calon Zul-Rohmi sebanyak 7 atau $21,2 \%$ isu politik, 3 atau $14,2 \%$ isu ekonomi, 1 atau $11,1 \%$ isu sosial dan $3,57 \%$ tentang profil kandidat

Frekuensi topik berita Pasangan Calon Suhaili-Amin sebanyak 7 atau $21,2 \%$ isu politik, 2 atau 9,5\% isu ekonomi, 1 atau $25 \%$ isu persaingan pemilihan

\section{Tabel.4.}

Frekuensi Unit Analisis Narasumber Berita Pasangan Calon berdasarkan hasil Coding Shet

\begin{tabular}{|l|c|c|c|c|c|c|}
\hline \multirow{2}{*}{$\begin{array}{c}\text { Pasangan } \\
\text { Calon }\end{array}$} & \multicolumn{5}{|c|}{ Frekuensi } & \multirow{2}{*}{ Total } \\
\cline { 2 - 7 } & Kandidat & $\begin{array}{c}\text { Tim } \\
\text { Kampanye }\end{array}$ & $\begin{array}{c}\text { Penyelenggara } \\
\text { Pemilu }\end{array}$ & $\begin{array}{c}\text { Tokoh } \\
\text { Masyarakat }\end{array}$ & Partai & \\
\hline Suhaili-Amin & 4 & 5 & 2 & 1 & 4 & 16 \\
\hline Akhyar-Mori & 19 & 1 & 1 & 6 & 5 & 32 \\
\hline Zul-Rohmi & 4 & 4 & 2 & 1 & 2 & 13 \\
\hline Ali-Sakti & 31 & 1 & 0 & 24 & 0 & 56 \\
\hline Total & 58 & 11 & 5 & 32 & 11 & 117 \\
\hline
\end{tabular}

Sumber: Data olahan penulis, 2018

Tabel datas menunujukkan frekuensi narasumber berita Pasangan Calon Ali-Sakti sebanyak 31 atau 53,4\% berasal dari Kandidat, 24 atau $75 \%$ dari tokoh masyarakat dan 1 atau 9,0\% dari Tim Kampanye, kemudian frekuensi narasumber berita Pasangan Calon Akhyar-Mori sebanyak 19 atau 32,7\% dari kandidat, 6 atau 18,7\% dari tokoh masyarakat, 5 atau 45,4\% dari partai, 1 atau $9 \%$ dari tim kampanye dan1atau 20\% dari penyelenggara pemilu.

Frekuensi narasumber berita Pasangan Calon Suhaili-Amin sebanyak 5 atau $45,4 \%$ dari tim kampanye, 4 atau 6,8\% dari kandidat, 2 atau $40 \%$ dari penyelenggara pemilu, 1 atau 3,1\% dari tokoh masyarakat, 4 atau 36,3\% dari partai. Kemudian frekuensi narasumber berita pasangan Calon Zul-Rohmi sebanyak 4 atau 6,8\% dari kandidat, 4 atau 36,3\% dari tim kampanye, 2 atau $18,1 \%$ dari partai, 2 atau $40 \%$ dari penyelenggara pemilu dan 1 atau $0,3 \%$ dari tokoh masyarakat 


\section{KESIMPULAN}

Perhitungan coding shet keseluruhan unit analisis isi berita Pilkada Gubernur dan Wakil Gubenur NTB Edisi 1-31 Maret 2018 pada Harian Suara NTB menunjukkan angka reliabilitas yang memadai dengan nilai antara 0,75 hingga 1,0 sehingga diperoleh hasil bahwa :

Frekuensi unit analisis yang menggambarkan bahwa frekuensi kandidat yang diberitakan adalah sebanyak 51,9\% Pasangan Calon Ali-Sakti, 24,03\% memberitakan Pasangan Calon Akhyar-Mori, 13,4\% memberitakan Pasangan Calon Zul-Rohmi dan 10,57\% memberitakan Pasangan Calon Suhaili-Amin. Perhitungan ini menunjukkan bahwa pemberitaan lebih condong kepada pasangan Calon Ali-Sakti dengan penempatan berita $100 \%$ berada di halaman depan (hide line) dengan narasumber pemberitaan sebanyak $75 \%$ dari tokoh masyarakat $53,4 \%$ dari kandidat melalui keterangan pers sebanyak 66,3\% dan $40 \%$ dari liputan langsung sedangkan topik berita $100 \%$ dengan isu ideologi, 96,4\% mengenai profil kandidat, $75 \%$ dengan isu persaingan pemilihan, $66 \%$ dengan isu sosial, $42 \%$ tentang isu ekonomi dan $15,5 \%$ dengan isu politik

Dengan demikian pemberitaan pasangan calon gubernur dan wakil gubernur NTB tahun 2018 masih kurang berimbang, sehingga netralitas media cetak Suara NTB terhadap pasangan calon dan penerapan Kode Etik Jurnalis Wartawan Indonesia dalam hal menyajikan berita secara berimbang perlu ditigkatkan.

\section{SARAN}

Dari hasil penelitian ini media cetak hendaknya selalu mengutamakan netralitas dalam pemberitaan pilkada, sehingga pemberitaan akan lebih berimbang dengan mencoba untuk tidak condong pada satu pasangan calon, hal ini penting agar media tidak digunakan sebagai salah satu "corong" dari pihak tertentu.

Pemerintah hendaknya lebih mampu memberikan pengawasan dan tindakan hukum yang tegas terhadap media masa yang ada di Indonesia. Dengan adanya hukum dan sangsi yang sesuai akan memberikan jaminan kepada media maupun masyarakat sehingga menjadi lebih baik lagi kedepannya. 


\section{DAFTAR PUSTAKA}

McQuail, Denis, 1987, Teori Komunikasi Massa, Erlangga, Jakarta.

Kusumaningrat, Hikmat dan Purnama Kusumaningrat.2012. Jurnalistik Teori dan Praktik. Bandung: PT. Remaja Rosdakarya

Syamsul, Asep M..Romli, S.IP.2016.Jurnalistik Praktis.PT. Remaja Rosdakarya

Eriyanto. 2011. Analisisi isi:Pengantar Metodologi Untuk Penelitian Ilmu Komunikasi dan Ilmu-Ilmu social Lainnya Kencana Prenada Media Group. Jakarta

Prof. Dr. Sugiyono. 2016. Metode Penelitian Kuantitatif, Kualitatif dan R\&D. Bandung: Alfabeta

Kriyantono, Rachmat. 2008. Teknis Praktis Riset Komunikasi.Kencana Prenada Media Group. Jakarta

Nurudin. 2007. Pengantar Komunikasi Massa. Jakarta : PT. Raja Grafindo Persada

Fathurrahman, Lalu. 2016. Pengantar Metodologi Penelitian Ilmu Sosial/Ilmu Komunikasi Fakultass Ilmu Sosial dan Ilmu Politik Universitas 45 Mataram

Imran, Hasyim Ali. 2012. Jurnal Studi Komunikasidan Media Vol. 16 No. 1 (Januari - Juni 2012): Media Massa Khalayak Media, the Audience Theory, Efek Isi Media dan Fenomena Diskursif (Sebuah Tinjauan dengan KasuspadaSuratKabar Rakyat Merdeka https://jurnal.kominfo.go.id/index.php/jskm/article/viewFile/160103/11.

Diakses pada tanggal, 15 Otober 2018, pukul PM 8:59:32

Setiawan, Aria Aditya. 2013. Peranan Media Massa dalam Meningkatkan Kualitas Kemerintahan Lokal Berbasis Human Security di Kota Jayapura, Journal. UniversitasDiponegoro.https://ejournal.undip.ac.id/index.php/politika/article/d ownload/5096/4621 Diakses pada tanggal, 16 Otober 2018, pukul 9:32:38 PM

https://id.wikipedia.org/wiki/Suara_NTB Diakses pada tanggal, 12/12/2018 pukul 1:45 PM 